\title{
Dicotomia, complexidade e educaçáo para a cidadania
}

Joel Haroldo Baade

https://orcid.org/0000-0001-7353-6648

Laude Erandi Brandenburg ${ }^{2}$

https://orcid.org/0000-0003-1249-9534

Juan Miguel González Velasco ${ }^{3}$

https://orcid.org/0000-0002-3502-2539

\section{Resumo}

A vida humana nas mais diferentes esferas, da organização social, passando pelo desenvolvimento das ciências, alcançando até mesmo elementos fundamentais das identidades individuais, foi marcada por um paradigma dicotômico, que produziu um modo binário de interpretar a realidade (certo e errado, rico e pobre, leste e oeste, norte e sul etc.). Este texto busca analisar as consequências desse pensamento binário e em que medida produz a injustiça social, especialmente no contexto educacional, vislumbrando, no paradigma da complexidade, uma alternativa para a construção de uma educaçáo e de uma sociedade mais cidadãs. Mas busca também por algumas possibilidades de rupturas com esses sistemas estruturados nos e pelos diferentes setores sociais, entre eles a educaçáo. Metodologicamente, a pesquisa pode ser caracterizada como de natureza básica em que se emprega o método indutivo. A seleçáo de fontes e autores é arbitrária na medida em que foram consideradas representativas das respectivas ideias desenvolvidas. Conclui-se que o pensamento complexo oferece alternativa ao pensamento binário em diferentes níveis educacionais, mas a sua efetivação em prática social é também desafio monumental, pois pressupóe a modificação de comportamentos profundamente arraigados na cultura e nas matrizes existenciais dos agentes sociais. Assim, cabe às instituiçóes educativas um papel de ruptura com essa dicotomia por meio de um projeto educacional voltado para a plena cidadania como exercício de justiça social.

Palavras-chave: Pensamento binário, Desigualdade social, Epistemologia, Escola, Justiça social.

1 Professor doutor dos Programas de Pós-Graduaçáo Profissional em Educaçāo Básica e Acadêmico em Desenvolvimento e Sociedade da Universidade Alto Vale do Rio do Peixe - UNIARP. Caçador, SC, Brasil. Email: baadejoel@gmail.com.

${ }^{2}$ Professora doutora do Programa de Pós-Graduaçáo em Teologia da Escola Superior de Teologia - EST. São Leopoldo, RS, Brasil. E-mail: laude@est.edu.br.

${ }^{3}$ Professor doutor do Programa de Pós-Graduaçáo da Faculdade de Ciências Farmacêuticas e Bioquímicas da Universidad Mayor de San Andres. La Paz, Bolívia. E-mail: jmgonzales9@umsa.bo. 


\section{Dichotomy, complexity and education for citizenship}

\section{Abstract}

Human life in the most different spheres, from social organization, through the development of sciences, reaching even fundamental elements of individual identities, was marked by a dichotomous paradigm, which produced a binary way of interpreting reality (right and wrong, rich and poor, east and west, north and south etc.). This text seeks to analyze the consequences of this binary thinking and the extent to which it produces social injustice, especially in the educational context, envisioning, in the complexity paradigm, an alternative for the construction of more citizen-like education and society. But it also searches for some possibilities of ruptures with these systems structured in and by the different social sectors, including education. Methodologically, the research can be characterized as of a basic nature in which the inductive method is used. The selection of sources and authors is arbitrary insofar as they were considered representative of the respective ideas developed. It is concluded that complex thinking offers an alternative to binary thinking at different educational levels, but its implementation in social practice is also a monumental challenge, since it presupposes the modification of behaviors deeply rooted in the culture and in the existential matrices of social agents. Thus, it is up to educational institutions to break with this dichotomy through an educational project aimed at full citizenship as an exercise of social justice.

Keywords: Binary thinking, Social inequality, Epistemology, School, Social justice.

\section{Introduçăo}

A vida, diferentemente das palavras cruzadas, compreende espaços sem definição, espaços com falsas definiçōes e, sobretudo, a ausência de um quadro geral fechado Edgar Morin

Vive-se em um mundo dividido. Em todos os tempos e lugares há muros que dividem as pessoas, delas mesmas e do mundo que as cerca. Há uma parábola que conta a estória de dois irmãos, que haviam se desentendido em algum momento de sua trajetória de vida. Eles moravam lado a lado e apenas um córrego separava as duas propriedades. Como não havia obstáculos que impedissem a vista, regularmente os irmãos viam um ao outro, o que produzia um sentimento incômodo. Certa vez, não mais disposto a suportar a vista do outro irmão, um deles resolve construir uma cerca. Para tal, adquire a madeira e contrata um carpinteiro para executar a obra. Este, por sua vez, ao invés de proceder à construção da cerca, utiliza a matéria-prima para construir uma ponte. Ao ver a ponte feita, o outro irmão a atravessa, vai ao encontro do 
mandante da obra, o abraça e agradece por ter tido a coragem e iniciativa de finalmente acabar com a rixa que os separava.

Por que se constroem cercas ao invés de pontes? Por que as pessoas vivem separadas umas das outras? Por que alguns vivem em suas grandes casas, com fartura e abundância, enquanto outros nem sequer casa têm? Por que alguns têm sucesso e outros nem mesmo possibilidade de sonhar com o sucesso têm, pois lhes falta cama para deitarem suas cabeças? E a educação? Estaria livre desse mundo que insiste em separar? Por que há escolas das quais saem pessoas de sucesso, para ocuparem as melhores posiçóes nas mais almejadas organizaçóes, e outras escolas nas quais mal se consegue permanecer quando chove, pois as goteiras tomam conta de seu interior?

Essas inquietaçôes movem a escrita deste texto. A ideia central fundase na questão dos paradigmas, a partir dos estudos de Thomas Kuhn (1998) e de Raynaut (2015), que discorrem sobre a dicotomia ser humano versus natureza, sobre a qual assentaria o pensamento ocidental.

Em seguida, analisam-se as repercussóes do pensamento binário no contexto educacional, que é entendido como produto e produtor de uma sociedade marcada pela injustiça social. Os estudos de Habermas (2012) e Pierre Bourdieu (2007) marcam as reflexóes deste segundo ponto do texto.

$\mathrm{Na}$ busca por alternativas para uma escola e sociedade mais justas, vislumbram-se, nas abordagens de Edgar Morin (2001), possibilidades para a proposição de um novo paradigma, o da complexidade. Por fim, discorre-se sobre os desafios da educação frente à complexidade em contraposição à realidade marcada pela injustiça social. A educação para a cidadania emerge, assim, como caminho para a superação da matriz dicotômica e edificação de uma nova sociedade caracterizada pela justiça social.

\section{Os paradigmas e o pensamento dicotômico}

A problemática dos paradigmas foi objeto de estudo de Thomas Kuhn (1998), sendo que eles podem ser entendidos como estruturas mentais elementares que determinam modos de pensar, entender e agir do ser humano no mundo. Por um lado, os paradigmas são determinantes para toda a vida humana, pois criam as pré-condiçóes e predisposiçóes nos agentes sociais para que a realidade se estruture segundo as premissas paradigmáticas. 
Por outro lado, os paradigmas são também resultado e produto da ação humana. Nesses termos, a existência dos paradigmas não impóe uma realidade inabalável e inalterável. $\mathrm{Na}$ medida em que eles permitem a construção de certo grau de certezas e, em decorrência, de segurança, permitem também o aprofundamento científico e tecnológico. Os paradigmas permitem a identificação e a concentração de esforços de um conjunto expressivo de sujeitos em torno de um objetivo comum, seja para o desenvolvimento de técnicas e tecnologias de aplicação de determinada teoria ou mesmo para o desenvolvimento de novas teorias (KUHN, 1998).

A existência dos paradigmas permite a concentração em detalhes muito específicos da realidade, seja para preencher as lacunas da teoria inicial ou então para resolver suas inconsistências. $\mathrm{Na}$ medida em que isso ocorre, abrem-se também as possibilidades para a instauração de dissidências e, na medida em que estas ganham adeptos, criam-se também as condições para as revoluçôes científicas que levarão ao surgimento de novos paradigmas (KUHN, 1998).

Essa ideia de Kuhn (1998) está ligada à concepção dos paradigmas nos diferentes setores sociais, inclusive na educação. Se no sistema de ensino o paradigma científico exerce um papel essencial, torna-se necessário falar da origem, da compreensão de paradigma científico e da forma como ele tem-se manifestado e transformado ao longo do tempo.

Segundo Claude Raynaut (2015), um dos paradigmas mais determinantes da sociedade ocidental é a dicotomia entre o ser humano e a natureza, que é considerado pelo autor como o fundador do pensamento científico. Cada um dos termos da oposição, em grande parte, segundo o autor, define-se em relação ao outro e "essa estrutura lógica binária [que dicotomiza ser humano e natureza] funciona como instrumento mental a partir do qual se organiza o olhar das sociedades sobre elas mesmas e sobre tudo o que as circunda" (RAYNAUT, 2015, p. 7).

O par binário ser humano/natureza tem as suas raízes na cultura ocidental. Embora haja grande riqueza nos modos de pensar e conhecer de outras civilizaçôes, a ciência, tal como é conhecida e praticada em âmbito internacional, não deixa de ser fruto da expansão política e econômica europeia ao longo dos séculos. Assim, desde a antiguidade grega, passando pelos encontros de culturas ocidentais e orientais, pela ascensáo e queda de impérios, produziu-se um apartamento do ser humano em relação à natureza. 
O ser humano cada vez mais passou a ser visto em oposição à natureza (RAYNAUT, 2015).

No contexto da religião cristá, o ser humano foi por muito tempo visto como o dono do mundo, o que, por sua vez, acabou inspirando, nas sociedades industriais, sua relação de dominação da natureza. $\mathrm{O}$ antropocentrismo renascentista já antes havia contribuído para reforçar a posição privilegiada do ser humano em relação ao mundo que o circunda. Nesta nova representação, a natureza deve ser observada e os seus traços e suas propriedades características devem ser conhecidas.

Do ponto de vista filosófico, a forma mais acabada da visão lógica, matemática e geométrica do mundo foi proposta, desde a primeira metade do século XVII, por Descartes. Segundo ele, todos os fenômenos que se pode observar na natureza são explicáveis mediante a aplicação da razão e remetem, por fim, a questóes de movimento e de cinética. $\mathrm{O}$ mundo não passa de uma grande máquina. Uma máquina particularmente complexa, mas cuja complexidade pode ser reduzida a alguns princípios inteligíveis (RAYNAUT, 2015, p. 25).

A laicização completa da ciência e a constituição de um campo científico dicotômico consolidou-se no final do século XVIII e ao longo do século XIX, particularmente no positivismo de Augusto Comte. Produziu-se aqui também o divórcio entre ciência, como campo de concepção do conhecimento, e técnica, como esfera de intervenção sobre a matéria (RAYNAUT, 2015).

A ciência tem cumprido com essa tarefa de organizar o processo do olhar da sociedade sobre si mesma e sobre a natureza como objetos de investigação. O objeto está fora, em outra esfera. Daí advém a dicotomia. Esse processo da Ciência incide sobre os diferentes setores socias e também sobre a educação.

\section{Uma educaçáo dicotômica}

Os reflexos do pensamento dicotômico se fazem sentir nos níveis da educação. Para evidenciar o quanto o pensamento dicotômico penetrou no solo onde deveria frutificar a escola, aborda-se a questão sob dois aspectos: a) a escola como produto e produtora de uma sociedade em que o mundo da 
vida é colonizado pela esfera sistêmica; e b) a escola como campo de reprodução de uma matriz disciplinar em currículo e práticas.

A ideia de colonização do mundo da vida pela esfera sistêmica foi desenvolvida por Jürgen Habermas em sua teoria da ação comunicativa. Segundo o autor (2012), a sociedade é constituída de uma base comum que permite aos indivíduos agirem coletivamente, em resposta aos obstáculos que o meio lhes impóe. Esta base comum é chamada de mundo da vida e é constituído da cultura, enquanto estoque de conhecimento que permite entender o mundo; da sociedade, como conjunto de ordenamentos que permitem a vivência grupal; e da pessoa, que são as competências que compóem as personalidades individuais (HABERMAS, 2012).

A sociedade humana, em seus estágios iniciais, era plenamente integrada e a religião desempenhava papel de destaque nesse processo. A ação intersubjetiva pela linguagem leva à necessidade de se buscar consensos. $\mathrm{Na}$ medida em que essa sociedade se torna mais complexa, produzindo a divisão do trabalho, conforme estudos de Durkheim (2010), ocorre também uma diferenciação estrutural do sistema social, mas não mais pelo consenso.

Assim, ao lado da forma tradicional de integração social baseada no consenso, surge uma nova forma de integração baseada em mecanismos autorregulados como o mercado ou a burocracia. A evolução social e a crescente racionalização do mundo da vida, implicando uma demanda emergente aos agentes sociais na coordenação de suas açóes mediadas linguisticamente, leva a uma sobrecarga destas mediaçôes. Esta sobrecarga dos processos comunicativos, somada à emergente diferenciação sistêmica, abre então caminho para os meios deslinguistificados, nomeadamente mercado e administração burocrática, assumirem cada vez mais as funçôes de coordenar as açóes, alijando para a periferia do sistema os processos comunicativos mediados linguisticamente (HABERMAS, 2012).

Os meios deslinguistificados mencionados por Habermas (2012) possuem uma estrutura binária e dicotômica, justamente para cumprirem de modo mais eficiente a sua finalidade, que é a de regular a vida dos sujeitos independentemente das consciências individuais. $\mathrm{Na}$ medida em que eles penetram também na escola, esta passa a funcionar, por um lado, como produto da sociedade cada vez mais coordenada pela esfera sistêmica; e, por outro, como produtora desta sociedade colonizada, pois condicionam os 
sujeitos que vivem em seu contexto a reproduzirem as práticas às quais são submetidos.

A colonização da escola pela esfera sistêmica pode ser observada no campo da didática. Ironicamente, o mesmo movimento que desde Rousseau enfatiza o papel do sujeito aprendente, que levou à Escola Nova e à didática decorrente desse movimento, forneceu também o fundamento ao liberalismo econômico, na medida em que pôs as bases científicas para explicar as diferenças dos sujeitos e as desigualdades na experiência escolar, como o fracasso, como próprias da natureza individual de cada criança. "Assim, a valorização da criança como sujeito da aprendizagem [...] contraditoriamente se impóe como justificativa da desigualdade escolar e social" (PIMENTA; ANASTASIOU, 2014, p. 45).

Nesse contexto, vale referência aos estudos de Pierre Bourdieu (2007) e sua referência ao conceito de habitus. O hábito é a predisposição para a ação independentemente da consciência do sujeito. Mesmo que, em algum momento, tivesse sido possível identificar determinados hábitos como característicos de épocas e sociedades, como pretendia Durkheim; para Bourdieu, na sociedade de classes, os hábitos também variam em função dessa mesma classe. Nessa sociedade já não há mais um consenso moral e cívico e, na prática, os valores cultivados pelos membros de uma e outra classe são bastante distintos. Não haveria mais, segundo Bourdieu (2007), valores universais partilhados por todos os cidadáos de uma determinada sociedade. A sociedade de classes é também norteada por uma matriz binária, por um paradigma dicotômico.

A escola, por sua vez, não está alheia a essa dinâmica da sociedade, pois é justamente a instituição social responsável pela preparação dos indivíduos para a vida coletiva. Assim, a escola torna-se lugar de embate das diferentes classes. Já não se pode sequer falar de "uma" escola, pois as diferenças entre as escolas brasileiras são abismais. Para se comprovar esta afirmação, basta rápida consulta ao Índice de Desenvolvimento da Educação Básica (IDEB), comparando as escolas com os melhores às escolas com os piores resultados em uma mesma região. O estudo de Ribeiro e Vóvio (2017, p. 76), que toma por base a Prova Brasil, corrobora esta constatação:

quanto maior os níveis de vulnerabilidade social do entorno do estabelecimento de ensino, mais limitada tende a ser a qualidade das 
oportunidades educacionais por ele oferecidas. [...] os alunos com baixos recursos culturais familiares que estudam em escolas de entorno mais vulnerável tendem a obter desempenho pior; em contrapartida, alunos com mesmos recursos culturais, quando estudam em contextos menos vulneráveis, obtêm desempenho melhor. A situação é equivalente para alunos com maiores recursos culturais: quando estudam em contextos mais vulneráveis, tendem a apresentar desempenhos piores.

Nesses termos, a escola aparece como "máquina infernal", que tem a única finalidade de selecionar, excluir, fabricar e multiplicar injustiças (VALLE, 2018). Diferentes mecanismos foram postos a serviço desse mecanismo cujo propósito é garantir a perpetuação das desigualdades decorrentes do modo dicotômico de concepção do mundo.

Patrice Canivez (1998) recorre a Foucault para denunciar a disciplina escolar como mecanismo de controle dos corpos, de modo a tornarem-se dóceis e, portanto, acomodados à estrutura social hegemônica. Com a disciplina, foi possível a instalação de uma ruptura entre discurso e prática na escola. Enquanto o discurso poderia valorizar os princípios mais nobres das sociedades humanas, na prática, vivenciava-se a injustiça, viabilizando a sedimentação dos hábitos que se desejava para cada tipo de pessoa dentro da sociedade dicotomizada.

A Lei de Diretrizes e Bases prevê, no seu Art 2o: “A educação, dever da família e do Estado, inspirada nos princípios de liberdade e nos ideais de solidariedade humana, tem por finalidade o pleno desenvolvimento do educando, seu preparo para o exercício da cidadania e sua qualificação para o trabalho". O velho artigo da lei, que em si mesma é letra morta, requer sua visibilidade na prática.

Assim, essas finalidades previstas para a educação podem ser alcançadas pela mutualidade de vários setores sociais no compromisso de educar, ou seja, partilhar, construir, produzir, modificar o conhecimento necessário para a vida de todas as pessoas. Em si, o conhecimento existe para e em função da vida, mas o processo de escolarização objetificou e engessou o conhecimento e o trancou nos muros escolares. Surgiu, então, um hiato entre o conhecimento acadêmico e o conhecimento cotidiano. As famílias remetem a educação ao processo escolar; e a escola exige da família sua responsabilidade na formação dos e das estudantes. 
Ao chegar na educação Profissional ou ao Ensino Superior, essa dicotomia continua. $\mathrm{O}$ conhecimento acadêmico pouco se coaduna com a vida cotidiana ou com o mercado de trabalho. $\mathrm{O}$ conhecimento escolar transforma-se em mero objeto dissociado do real. E os paradigmas em vigor são simplesmente reproduzidos, apropriados de forma mecanicista sem alcançar a aprendizagem.

Tem-se, assim, sob diferentes aspectos, uma educação marcada por uma matriz de pensamento e prática dicotômica, binária, que produz e reproduz as desigualdades. Cabe, então, perguntar por alternativas, tendo em vista que a escola não é apenas vista como reflexo da sociedade que a circunda, mas também como espaço de construção da cidadania e de uma nova sociedade.

\section{O pensamento complexo}

O pensamento complexo em geral é uma proposta filosófica baseada em princípios propostos há vários anos, mas que, à medida em que se consagra na prática educativa, sugere diversas interpretaçóes, aplicaçóes e ideias. Por outro lado, religar é um conceito moriniano, já que em diversos discursos, o professor Edgar Morin fala de religar a vida, religar o pensamento, entre outros (MORIN, 2011).

Um dos processos que o pensamento complexo e em geral a complexidade, através do processo metodológico da transdisciplinaridade construído, e que nos últimos anos é relevante para entender como se pode aplicar este paradigma emergente na educação, é aplicando a religação, entendida como unir e desunir o conhecimento em função do relacional ou no relacional para desconstruir algo.

Essa maneira de pensar assim, é o que se chama pensamento religado como ferramenta prática, que permite que o pensamento complexo e, mais ainda, o pensamento sistêmico operem na cabeça dos educandos. Um sistema ou subsistema em seus componentes, em sua funcionalidade e recursividade é pouco entendível se não religa seu existir e sua função.

Pensamento religado é pois, uma maneira de correlacionar nossa existência e nossas atividades cotidianas e científicas, é uma ferramenta que permite chegar à transdisciplinaridade de una maneira mais fácil e prática. 
É muito interessante por nome nas açôes, mas, sem dúvida, que dia a dia religamos nossa vida, nossas atitudes, feitos, conceitos, fenômenos e em geral tudo o que fazemos na vida, sem querer passamos de um processo comunicacional a sentimentos encontrados; e estes, por sua vez, a questôes econômicas, que afetam nossa conduta e, por sua vez, nossos feitos sociais. Geramos uma metodologia para fazer que nossa razão e nosso pensamento façam com que nossa personalidade como seres humanos flua em uma religação social (GONZÁLEZ, 2012).

O interessante também é que a mesma história da ciência faz com que vejamos como as disciplinas, as contribuiçôes científicas e sobretudo as profissóes se unam em suas descobertas, e é irreal pensar que muitas descobertas, por exemplo, não nasceram em sua disciplina tal, é o caso das ciências biológicas, da física ou das ciências sociais. Pensar religado é, pois, uma maneira cotidiana de viver, de fazer ciência, construir, separar e desconstruir conceitos, ideias, pensamentos e, sobretudo, conhecimentos.

É assim como o mundo, em sua cotidianidade é religado, religião, ciência, magia não se veem separadas, senão religadas, o conhecimento, o poder e a ideologia se veem como componentes naturais de uma realidade religada. Tudo coexiste de um nível de organização se, em seu mundo natural e social e também se veem como unidos por pontos que jamais pensaríamos existir, nesse sentido, o concreto e o abstrato coexistem em sua religação. $\mathrm{O}$ exemplo mais claro temos no mundo da comunicação e a famosa era digital, uma rede social não é outra coisa que uma religação humana de ideias e conceitos e formas de agir.

No entendimento da origem etiológico de uma doença, às vezes, a causa não está no biológico ou no físico, mas em condutas ou padróes sociais, é incrível como o mundo religa e religa sua existência. Nesse momento, seria possível que o pensamento religado existe em sua maneira natural como um elemento natural, uma ferramenta da razão e da complexidade, o desafio é dar-lhe maior forma, didática e diálogo.

Por outro lado, a transdisciplinaridade, a partir de sua concepção, permite ao estudante aproximar-se do mundo da disciplina, de sua diversidade, de sua unidade e de como se pode religar para a construção de um novo conhecimento (NICOLESCU, 2009). Nessa ordem de ideias, o conceito de realidade é uma parte operativa da didática de aula, que deve ser incorporada aos processos de aprendizagem e ensino dos estudantes. É 
necessário passar de um conceito de realidade da física a uma realidade educativa. O certo é que o conceito de transdisciplinaridade permite ver que não é possível conceber um sujeito imerso na hiperespecialidade e no mundo do mínimo na vida. A transdisciplinaridade é uma ferramenta que o educador e o educando devem utilizar para compreender a maneira em que se tece o mundo, a natureza, o ser humano e a ciência.

\section{Por uma educaçáo para a cidadania}

O conceito de cidadania no contexto da presente discussão não é aleatório. Vislumbra-se, na cidadania, a possibilidade de transcendência do pensamento e sociedade organizada dicotômica e binariamente. O ser humano é um ente social. Ele não se cria e não vive sozinho. Depende dos seus pares para aprender e se desenvolver. A sua identidade é definida justamente no encontro com o outro. Por ser um ser social, precisa organizar esta vida de tal modo que ela possa justamente chegar a sua plenitude ao lado de outras pessoas.

Assim, a cidadania é compreendida nesse contexto como expressão de pertença a esta coletividade. Nesses termos, o conceito é mais do que expressão jurídica, pois encerra em si a totalidade da vida. A educação, por sua vez, emerge como instituição social que promove a inserção deste sujeito na vida coletiva. Portanto, educação, a rigor, não é outra coisa senão a educação para a cidadania.

Desse modo, caso a escola se torne instrumento de reprodução de um paradigma que produz a segregação e a injustiça, impedindo o desenvolvimento pleno dos sujeitos na sociedade a que pertencem, deixa também de cumprir o se papel primordial.

Como uma tentativa de superar essa visão fragmentária e a prática dicotômica, começaram a surgir movimentos na área da educação de relacionar os paradigmas com a vida real da escola, onde são reproduzidos ou aplicados os paradigmas, e um diálogo das áreas de conhecimento separadas entre si.

O primeiro movimento foi pela busca de interdisciplinaridade (FAZENDA, 1994). Esse movimento nasceu na França na década de 1960 e se iniciaram as discussóes no Brasil na década de 1970. Na década de 1980, 
houve uma estruturação básica desse ideário e, nos anos 1990, adentrou às legislaçóes e às estruturaçóes curriculares decorrentes.

Os temas transversais lançados com os Parâmetros Curriculares Nacionais são: Ética (Respeito mútuo, Justiça, Diálogo, Solidariedade); Orientação Sexual; Meio Ambiente; Saúde; Pluralidade Cultural; e Temas Locais. O objetivo consistia em perpassar esses aspectos da cidadania em todos os componentes curriculares de forma transversal ou em forma de projetos, que eram abordados de forma multidisciplinar (BRASIL, 1998).

A Multidisciplinaridade busca a vista de um mesmo objeto de estudo sob diferentes óticas. Enquanto os temas transversais são assumidos em um ou outro componente, a mutidisciplinaridade envolve diferentes áreas do conhecimento sobre o mesmo foco conceitual. No entanto, nesse tipo de abordagem, conserva-se a separação entre áreas de conhecimento. Edgar Morin, em seu livro "Cabeça bem feita" (2001), aborda esse tratamento fragmentário criado pela disciplinarização do conhecimento e aponta para a importância do conceito organizador sistêmico que articula diferentes conhecimentos por meio do que chama de ecociência (MORIN, 2001, p. 110s.).

"Certas noçôes circulam e, com frequência, atravessam clandestinamente as fronteiras, sem serem detectadas pelos 'alfandegueiros '" (MORIN, 2001, p. 108). E isso implica ou implicaria em que os mesmos conceitos circulem entre os diferentes campos e os façam dialogar. Essa superação das fronteiras entre as áreas, ao adentrar a escola de educação básica, auxiliaria no impacto sobre a sociedade e, dessa forma, poderia provocar um exercício de cidadania.

A escola é um lugar de aprendizagem da cidadania (GRILLO et al., 2008). Contudo, o seu lugar na vanguarda da construção de uma sociedade com os atributos do que se pode chamar de real desenvolvimento, marcada pela democracia, diálogo, consensos e dissensos, em que se valorize e respeite a alteridade, ainda precisa superar a pura retórica. Nessa construção, está certamente a educação pública, gratuita e da qualidade. Muitas vezes, segundo Pimenta e Anastasiou (2014), essa retórica tem se traduzido justamente na ampliação dos sistemas privados de educação, sendo que a manutenção do sistema público de ensino estaria somente a serviço do atendimento burocrático dos anseios populares. Nesses moldes, a educação pouco contribui para a efetivação da justiça social. 
Considera-se grande desafio à educação o reconhecimento de que as açôes dos sujeitos na escola, seja em sala de aula ou fora dela, são guiadas pelas concepçóes que esses mesmos sujeitos têm sobre como se aprende (GRILLO et al., 2008). A Teoria do Conhecimento, portanto, deve encontrar o seu lugar no cotidiano da escola. As fronteiras entre o que é discussão relativa apenas a uma parcela seleta de intelectuais e o que se discute no dia a dia da escola devem ser superadas. Escola não é apenas lugar de transmissão de conhecimento, mas é espaço propício de construção e inovação.

Assim, a educação que ocorre na escola é mais do que treinamento profissional ou reprodução, ela é prática social.

O ensino, fenômeno complexo, enquanto prática social realizada por seres humanos com seres humanos, é modificado pela ação e relação destes sujeitos - professores e alunos - historicamente situados, que são, por sua vez, modificados nesse processo. Então nos parece mais interessante compreender o fenômeno do ensino como uma situação em movimento e diversa conforme os sujeitos, os lugares e os contextos onde ocorre. Nessa perspectiva, não é possível dissecá-lo, para então operá-lo (PIMENTA; ANASTASIOU, 2014, p. 48).

Nessa perspectiva, Grillo et al. (2008) reforçam a importância de uma reflexão sobre a prática docente como uma nova racionalidade. Sob a ótica do professor, portanto, tem-se que ele é construtor de conhecimento, não apenas no campo da disciplina/área de conhecimento em que atua, mas também da prática de ensinar. Com isto, por sua vez, não apenas aperfeiçoa sua prática profissional, como também passa a atuar como o produtor de um novo habitus entre os alunos, que tendem a reproduzir o que vivenciam na escola. $\mathrm{O}$ conviver com profissionais reflexivos condiciona para a formação de um hábito reflexivo, fundamental à cidadania.

A busca, portanto, constitui-se em imperativo irrevogável da práxis docente. A complexidade e a dinamicidade, cristalizadas na forma de incertezas, marcam o cotidiano educacional, fazendo com que haja a cada momento respostas novas. Isso é corroborado por Freire (1996, p. 160):

E ensinar e aprender não podem dar-se fora da procura [...]. O nosso é um trabalho realizado com gente, miúda, jovem ou adulta, mas gente em permanente processo de busca. Gente formando-se, mudando, 
crescendo, reorientando-se, melhorando, mas, porque gente, capaz de negar os valores, de distorcer-se, de recuar, de transgredir.

No Brasil, a Lei de Diretrizes e bases de 1996 lançou fundamentos para algumas mudanças a serem implementadas no século XXI na educação brasileira. A partir do movimento no mundo todo para buscar a superaçáo das realidades educacionais dicotômicas e impulsionados pelos estudos da Unesco pelos textos do livro "Educação - um tesouro a descobrir" (coordenado por Jacques Delors) e pelo livro de Edgar Morin "Os Sete saberes necessários à educação do futuro", as leis complementares que foram surgindo no Brasil encamparam essas novas tendências.

Documentos e legislações na área da Educação inclusiva, consideração das diferentes deficiências nos processos pedagógicos e a própria Base Nacional Comum Curricular - BNCC aportam elementos da educação humanizadora e integradora. A BNCC passou por processo de escuta popular além da consulta a diferentes especialistas das áreas das universidades.

Evidentemente, a BNCC continuou na linha das competências, grande tendência mundial, que também recebe suas críticas, mas, ao mesmo tempo, representa alguns avanços na tendência fragmentária anterior. As competências gerais, válidas para docentes e discentes, presentes nesse documento, podem representar um avanço no que tange ao protagonismo e ao desenvolvimento da cidadania. A $10^{\text {a }}$ Competência trata, justamente, da Responsabilidade e Cidadania, que seria a culminância da vida de cidadãos e cidadãs. Aliás, outra competência, a 9a, Empatia e Cooperação, pode também vir a lançar alguma base para uma possível justiça social ligada ao processo de aprendizagem escolar.

A busca por justiça social náo se restringe a grupos ou movimentos envolvidos na superação de uma sociedade dicotômica, separada em ricos e pobres por uma economia calcada na divisão entre forças produtivas de massa e as camadas privilegiadas. A justiça social, como propósito, pode ser, inclusive, encontrada nos objetivos do Banco Mundial - BM.

No entanto, o BM, que financia a educação, principalmente em países em desenvolvimento ou que se encontram em dificuldade, coloca como um de seus objetivos para o processo educacional o crescimento econômico do país, o que significa "seguir orientando o caráter e os rumos das políticas educacionais no país no sentido de manter e aprofundar a hegemonia de seu 
modelo de educação e sociedade em todo o mundo" (MOTA, MAUÉS, 2014, p. 1147). E isso está ligado à ideia de que a "teoria do capital humano é a de que um acréscimo marginal de instrução, treinamento e educação, correspondem um acréscimo marginal de capacidade de produção" (MOTA, MAUÉS, 2014, p. 1147)

O foco do financiamento da educação é, pois, aumentar a capacidade produtiva do país. Acredita-se ainda, como afirmou o presidente do BIRD, James Wolfensohn (1999), que esse tipo de investimento e de perspectiva educacional vá criar oportunidades para que as pessoas pobres se desenvolvam, de modo que se alcance justiça social e estabilidade econômica (ALTMANN, 2002, p 86).

No entanto, o pensamento binário continua a ser executado quando a economia aprofunda o hiato entre as pessoas e não lhes permite um acesso igualitário aos bens produzidos e, em decorrência, ao exercício pleno da cidadania. Então, cabe ao Ensino Superior, especialmente à pesquisa, e também à Educação Básica continuar buscando novos caminhos e possibilidades.

Nesse sentido, uma possibilidade de novo caminho na educação tem sido a tendência pedagógica ecossistêmica. Suanno e Freitas (2016, p. 87) descrevem nos seguintes termos este projeto:

[...] possibilitar condiçóes de aprendizagem que considerem as categorias contexto, contexto global, multidimensional e complexo, pois, dessa maneira, o conhecimento torna-se pertinente para o aluno, criando condiçôes para a compreensão das questôes mais amplas da sociedade e uma possível intervenção para a prevenção e solução de problemas, exercendo, assim, uma cidadania crítica. Para que isso seja possível, a escola deve valorizar práticas inter e transdisciplinares que favoreçam a construção colaborativa do conhecimento.

O paradigma ecossistêmico tem se cristalizado na proposta metodológica dos Projetos Criativos Ecoformadores (PCEs) e nas Escolas Criativas, idealizadas inicialmente por Torre e Zwierewicz (2009) e Torre (2013). Nas escolas criativas estimula-se o desenvolvimento da consciência, dos valores e da criatividade, que são elementos fundamentais para a existência cidadã. Tem-se aí exemplos de que outros modos de constituição social são possíveis além dos modelos norteados pelo paradigma dicotômico, 
especialmente em sua matriz neoliberal. A justiça social, portanto, tem início com a reforma do pensamento, com a desconstrução de cercas, muros e paredes, e a edificação de pontes que possam religar o que está separado. Embora não se possa delegar à escola a única responsabilidade pela construção dessa nova sociedade, é inegável o seu papel central nesse processo.

\section{Consideraçóes finais}

Iniciou-se a presente análise indagando pelas consequências do pensamento binário e em que medida ele produz a injustiça social, especialmente no contexto educacional. Diante disso, procurou-se vislumbrar no paradigma da complexidade uma alternativa para a construção de uma educação e uma sociedade mais cidadãs. Nessa trajetória, buscou-se também tecer reflexóes como forma de oportunizar rupturas com esses sistemas estruturados nos e pelos diferentes setores sociais, entre eles a educação, que muitas vezes apenas reproduzem e com isso consolidam a injustiça social. A educação para a cidadania emerge aqui como possibilidade para a edificação de uma sociedade na qual vigore a justiça social.

A Educaçáo Básica é um período importante para a aprendizagem e a vivência de cidadania. Por ser de cunho obrigatório para governos e sociedades, é também oportunidade de concretização do acesso esperado para todas as pessoas, embora algumas tenham mais e melhor acesso aos conhecimentos escolarizados e aos bens culturais do que outras. Além do acesso à Educação Básica, também o acesso à Educação Profissional e ao Ensino Superior são formas de romper com o dualismo característico da sociedade de classes. O processo de escolarizaçáo nesses diferentes níveis de escolarização pode constituir-se como importante espaço de tecer junto vários elementos do contexto social, assim como Morin (2001) compreende o complexus - tecido junto.

Ainda não se sabe o impacto real da teoria das competências presente na nova BNCC, pois é ideia ainda recente na História da Educação, mas pela ruptura das fronteiras entre conhecimentos ou pela superação do dualismo social espera-se estar construindo o processo de cidadania. Diante das dicotomias reais e construídas pelo pensamento moderno, a pesquisa e o ensino tanto na Educação Básica como no Ensino Superior podem ser artífices, construtores de pontes, de possibilidades de unir o que esteve 
separado por tantos séculos de dicotomia. Desconstruir paradigmas ou modificá-los pode levar tempo, mas novos paradigmas e tendências podem ser construídos à guisa de ponte. Diferentes e múltiplos projetos, por menores que sejam, podem ser insumos para a construção dessa ponte. Paulo Freire diria: é um ir-se-fazendo com esperança.

\section{Referências}

ALTMANN, Helena. Influências do Banco Mundial no projeto educacional brasileiro. Educação e Pesquisa, São Paulo, v.28, n.1, p. 77-89, jan./jun. 2002. BOURDIEU, Pierre. O Poder Simbólico. 10. ed. Rio de Janeiro: Bertrand Brasil, 2007.

BRASIL. Base Nacional Comum Curricular. Brasília: MEC, 2017. Disponível em: http://basenacionalcomum.mec.gov.br/images/BNCC_20dez_site.pdf. Acesso em: 09 de setembro de 2020.

BRASIL. Parâmetros Curriculares Nacionais. Brasília, DF: MEC/SEF, 1998.

CANIVEZ, Patrice. Educação o Cidadão? 2. ed. Campinas: Papirus, 1991.

DURKHEIM, Émile. Da divisão do trabalho social. 4. ed. São Paulo: WMF Martins Fontes, 2010

FAZENDA, Ivani. Interdisciplinaridade: história, teoria e pesquisa São Paulo: Papirus, 1994.

GONZÁLEZ, J. Teoría Educativa Transcompleja. Barranquilla: Universidad Simón Bolivar, 2012. Tomo I.

GRILLO, M.; FREITAS, A.L.; GESSINGERT, R.; LIMA, V.M. (Orgs.). $A$ gestáo da aula universitária na PUCRS. Porto Alegre: Edipuc, 2008. Disponível em: http://www.pucrs.br/edipucrs/agestaodaaula.pdf. Acesso em: 21 jul. 2020.

HABERMAS, Jürgen. Teoria do agir comunicativo. São Paulo: Martins Fontes, 2012. 2 v.

MORÍN, E. Introducción al Pensamiento Complejo. Madrid: Editorial Gedisa. 2011. 
MORIN, Edgar. A cabeça bem feita: repensar a reforma, reformar o pensamento. 3. ed. Rio de Janeiro: Bertrand Brasil, 2001.

MOTA JÚNIOR, William Pessoa da; MAUÉS, Olgaíses Cabral. O Banco Mundial e as Políticas Educacionais Brasileiras. Educação \& Realidade, Porto Alegre, v. 39, n. 4, p. 1137-1152, out./dez. 2014.. Disponível em: <http://www.ufrgs.br/edu_realidade>

NICOLESCU, B. Quést-ce que la réalité? Montreal: Liber, 2009.

PIMENTA, Selma Garrido; ANASTASIOU, Léa das Graças Camargos. Docência no Ensino Superior. 5.ed. São Paulo: Cortez, 2014.

RAYNAUT, Claude. Dicotomia entre ser humano e natureza: paradigma fundador do pensamento científico. In: PHILLIPPI Jr., Arlindo; FERNANDES, Valdir. Práticas da Interdisciplinaridade no ensino e pesquisa. Barueri, SP: Manole, 2015. p. 3-35.

RIBEIRO, Vanda Mendes; VOVIO, Cláudia Lemos. Desigualdade escolar e vulnerabilidade social no território. Educar em Revista, Curitiba, n. spe.2, p. 71-87, set. 2017. Disponível em: https://doi.org/10.1590/0104-4060.51372. Acesso em: 1 set. 2020.

SUANNO, Marilza Vanessa Rosa; FREITAS, Carla Conti de (Org.). Razão sensivel e complexidade na formação de professores: desafios transdisciplinares. Anápolis: UEG, 2016.

TORRE, Saturnino de la. Movimento de escolas criativas: Fazendo parte da história de formação e transformação. In: ZWIEREWICZ, Marlene (Org.). Criatividade e inovação no Ensino Superior: experiências latino-americanas e europeias em foco. Blumenau: Nova Letra, 2013.

TORRE, Saturnino de la; ZWIEREWICZ, Marlene. Projetos Criativos Ecoformadores. In: ZWIEREWICZ, Marlene; TORRE, Saturnino de la. Uma escola para o século XXI: escolas criativas e resiliência na educação. Florianópolis: Insular, 2009.

VALLE, Ione Ribeiro. (In)justiça escolar: os paradoxos do processo de democratização e a desigualdade distributiva das oportunidades de acesso à escola e à universidade. Revista Linhas. Florianópolis, v. 19, n. 41, p. 325-349, 
set./dez.

2018.

Disponível

em:

http://dx.doi.org/10.5965/1984723819412018325. Acesso em: 1 set. 2020.

Recebido em: 27 ago. 2020

Aceito em: 15 set. 2020 